\title{
Mineraçãão
}

\section{Efeito da dispersão em polpas de minérios itabiríticos}

\section{Dispersion effect on itabirite ores}

\author{
Adriano Raimundo Totou \\ Engenheiro de Minas da CSN, \\ mestrando do programa de Pós-Graduação \\ em Engenharia Mineral. \\ adriano.totou@csn.com.br
}

\author{
Carlos Alberto Pereira, Dr. \\ Professor do Departamento \\ de Engenharia de Minas da UFOP. \\ pereira@demin.ufop.br
}

Philipe Gonçalves Fernandes Machado

Graduando em Engenharia de Minas

no Departamento de Engenharia

de Minas da UFOP.

pgfmachado@yahoo.com.br

\author{
Carlos Adolpho Magalhães Baltar \\ Dr., Professor do Departamento \\ de Engenharia de Minas da UFPE. \\ camb@ufpe.br
}

\section{Resumo}

A flotação reversa do minério de ferro é antecedida de uma operação de deslamagem, cuja eficiência aumenta com o uso de um reagente que promova a dispersão da polpa. O trabalho avaliou a influência do tipo e da concentração do dispersante na eficiência da dispersão e nos resultados da flotação. Os resultados foram avaliados em termos de tamanho das partículas da lama, grau de dispersão e Índice de Seletividade de Gaudin, obtido na flotação. Os resultados mostram a importância da dispersão antes da deslamagem e sugerem que o reagente escolhido, como dispersante, não pode ser depressor para o quartzo. $\mathrm{O}$ hidróxido de sódio parece ser a melhor alternativa entre os reagentes testados.

Palavras-chave: Dispersão, deslamagem, seletividade na flotação.

\begin{abstract}
The reverse flotation of iron ores is preceded by a desliming stage whose efficiency increases with the use of reagents that promote the dispersion of the pulp. The present study addressed the influence of the type and of the concentration of the dispersant on the dispersion efficiency and on the flotation results. The results were appraised in terms of the slime's particle sizes, the dispersion degree and the Gaudin's Selectivity Index obtained in the flotation experiments. The results show the importance of the dispersion before the desliming stage and also suggest that the selected dispersants must not be quartz depressants. Sodium hydroxide seems to be the most effective among the tested reagents.
\end{abstract}

Keywords: Dispersion, desliming, flotation selectivity.

\section{Introdução}

A deslamagem antecedendo a flotação é prática industrial estabelecida há mais de 50 anos, introduzida na flotação catiônica reversa de minérios de ferro com o processo USBM (Clemmer, 1947).

As partículas finas tendem a agregarse ou a recobrir as partículas grossas (slimes coating). Em ambas as situações, dificultam a realização de uma deslamagem eficiente, passando parcialmente para a etapa de flotação, onde causam uma série de problemas (Baltar, 2008), sendo o consumo excessivo do coletor o que mais afeta a eficiência do processo em plantas de flotação para minério de ferro. O termo deslamagem, que se refere à eliminação de lamas indesejáveis para a operação unitária subseqüente (por exemplo, flotação ou separação em meio denso), é um tanto vago em termos granulométricos. Geralmente significa a eliminação de uma grande quantidade de material fino, sem uma conotação de separação granulométrica precisa ou eficiente. Um adequado grau de dispersão das partículas na polpa é requisito essencial para uma deslamagem eficiente. Uma maneira simples, mas onerosa, para se conseguir um alto grau de dispersão é elevar o pH mediante altas dosagens de $\mathrm{NaOH}$, aumentado a repulsão 
eletrostática entre as partículas. Experimentos de laboratório simples e confiáveis fornecem uma correlação entre grau de dispersão e eficiência de deslamagem, constituindo-se em ferramenta útil para predição do desempenho na flotação. As aminas adsorvem-se por atração eletrostática, portanto de forma não específica. Os finos, por terem maior energia superficial, consomem a maior parte do coletor impedindo uma flotação eficiente do quartzo. Desta forma, a presença de finos na flotação resulta em maiores contaminações e menor teor de ferro no concentrado.

Uma tentativa de minimizar o problema anteriormente descrito é através da elevação do nível de estabilidade do sistema, via adição de eletrólitos inorgânicos (dispersantes) e ou polieletrólitos, que po-

\section{Materiais e métodos}

Amostras de minério itabirítico foram obtidas através da classificação mecânica, coletadas no fluxo de overflow de classificador em espiral, onde $90 \%$ das partículas estão abaixo do diâmetro de corte em 0,15 mm. Tais amostras foram dem se adsorver seletivamente nos minerais de ganga. Subseqüentemente efetua-se uma deslamagem, através da qual se eliminam os finos que prejudicam a etapa de flotação. Um elevado grau de dispersão das partículas na polpa é essencial para uma deslamagem eficiente, que, por sua vez, é requisito para seletividade na flotação em sistemas envolvendo não-sulfetos. Investigações sobre o efeito do estado de dispersão das partículas em polpas são mais raras (Luz \& Araujo, 1988).

$\mathrm{O}$ uso de um reagente dispersante é importante porque possibilita a desagregação das partículas, permitindo uma deslamagem mais eficiente. Os dispersantes atuam no sentido de provocar o aumento da repulsão elétrica entre as partículas (por exemplo metafosfato de sódio e silicato de sódio) ou de promover uma estabilização estérica (por exemplo, carboximetilcelulose e poliacrilato).

São vários os agentes dispersantes utilizados para manter a estabilidade do sistema, podendo ser orgânicos e inorgânicos. Os dispersantes atuam aumentando a carga da dupla camada elétrica em função da adsorção na superfície das partículas por ligações de hidrogênio ou outro tipo de adsorção química (Rabelo, 1994).

Esse trabalho descreve o comportamento de minérios itabiríticos frente aos processos de deslamagem e flotação, tendo sido realizados estudos de caracterização e ensaios de determinação do grau de dispersão em polpas de minérios itabiríticos e de deslamagem e flotação nas melhores condições de dispersão. preparadas conforme o fluxograma ilustrado na Figura 1, onde estão representados o esquema de preparação da amostra, a realização dos testes tecnológicos em bancada e a caracterização dos produtos. A análise granulométrica da amos-

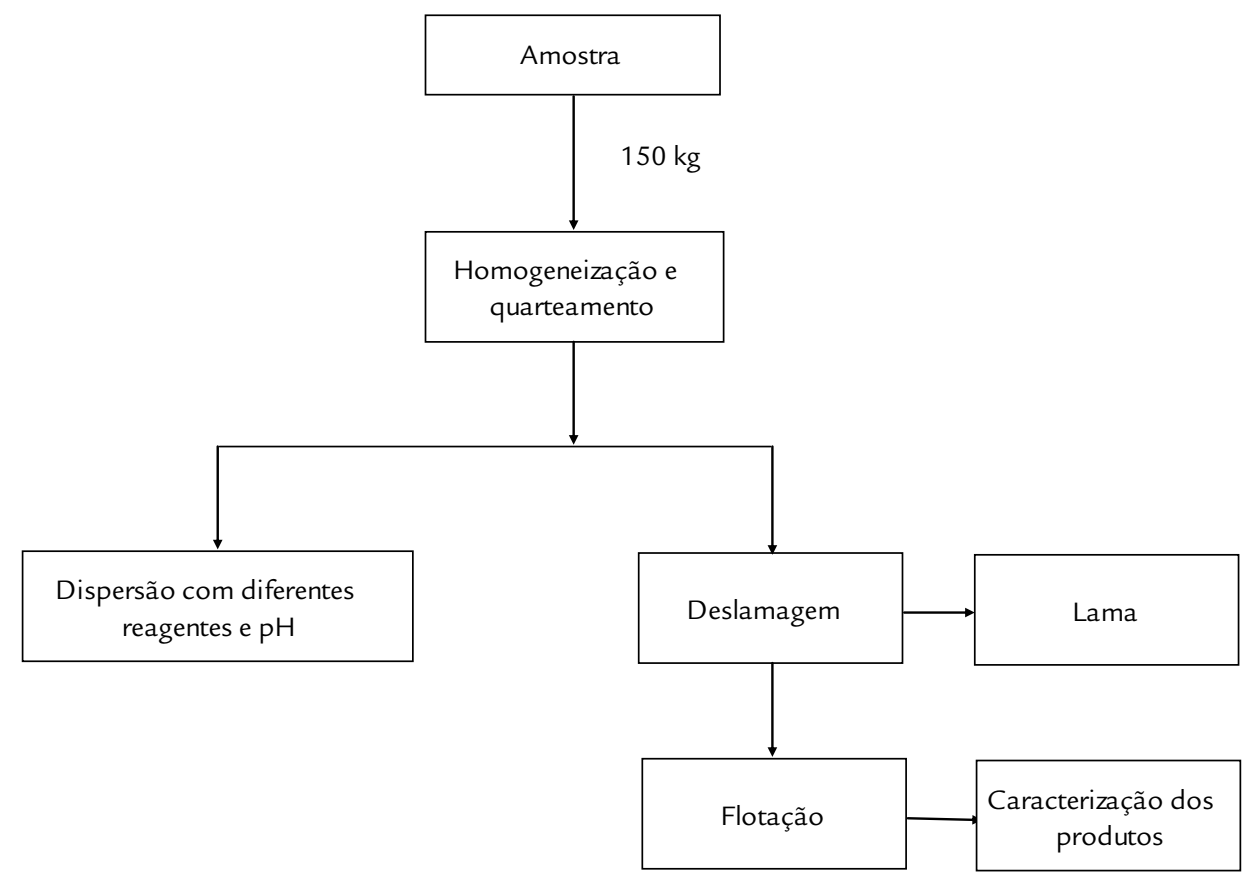

\section{Análise mineralógica}

Microscopia ótica de luz refletida

foi utilizada para a caracterização mi-

\section{Ensaios de dispersão e flotação}

Nos ensaios de dispersão, usou-se cerca de $5 \mathrm{~g}$ do minério. Também foram utilizados os reagentes hidróxido de sódio $(\mathrm{NaOH})$, hexametafosfato de sódio, silicato de sódio, metassilicato de sódio e poliacrilato de sódio, adicionados em um tubo de sedimentação de $200 \mathrm{~mL}$. Esse aparelho consta de um tubo de tra foi realizada a úmido e, utilizando-se o seguinte conjunto de peneiras: 2,$4 ; 1,0$; 0,$50 ; 0,25 ; 0,15 ; 0,106 ; 0,075$ e 0,045 $\mathrm{mm}$. A análise foi realizada a úmido com o auxílio de um peneirador vibratório suspenso de laboratório do tipo "Ro-Tap".

Figura 1

Fluxograma de preparação das amostras.

neralógica global da amostra.

vidro de 4,5 cm de diâmetro e $18,5 \mathrm{~cm}$ de altura, com uma saída de $0,5 \mathrm{~cm}$ de diâmetro para o sobrenadante a $1,5 \mathrm{~cm}$ do fundo do tubo. O tubo é instalado 
sobre um agitador magnético que realiza a agitação da polpa mediante uma barra magnética. O controle do $\mathrm{pH}$ foi efetuado através da imersão do eletrodo na polpa, na parte superior do tubo. $\mathrm{O}$ ajuste do $\mathrm{pH}$ foi feito na fase inicial de cada experimento e o eletrodo era retirado do tubo de sedimentação quando se certificada que o $\mathrm{pH}$ estava no valor

$M$ = massa de overflow em gramas

$M_{u f}=$ massa de underflow em gramas.

Todos os experimentos foram realizados em duplicata. Para o hidróxido de sódio, a variável foi o $\mathrm{pH}$ (desde natural até 11,0$)$ e, para os demais reagentes,

\section{Resultados e Discussão}

As amostras foram caracterizadas quimicamente pelo método de fluores-

cência de raios $\mathrm{X}$. Os resultados são apresentados na Tabela 1. O resultado desejado, para que este não influenciasse no processo de sedimentação das partículas em suspensão.

Terminados os cinco minutos de condicionamento e/ou agitação, desligava-se o agitador magnético, permitindose, assim, que a polpa ficasse em regime de sedimentação por mais um minuto. Depois desse intervalo, esgotava-se o foi utilizada a dosagem mínima de 300 g/t e máxima de $1200 \mathrm{~g} / \mathrm{t}$. Os melhores resultados da dispersão foram utilizados nos testes de deslamagem e flotação em sobrenadante através de um orifício situado a $1,5 \mathrm{~cm}$ da base do tubo. Em seguida, secavam-se e pesavam-se as alíquotas obtidas (a massa dispersa e a massa afundada).

A estabilidade das suspensões foi avaliada em termos de grau de dispersão (GD) das partículas presentes na polpa, dado pela expressão: bancada. As dosagens de coletor, amina, foram de 25 a $30 \mathrm{~g} / \mathrm{t}$ e de depressor, amido, foram de 600 a $800 \mathrm{~g} / \mathrm{t}$.
Tabela 1

Análise química global da fração $-0,15 \mathrm{~mm}$

Figura 2

Distribuição granulométrica da amostra de minério estudada.

Tabela 2

Quantificação mineralógica global da amostra-fração $<0,15$ mm

Legenda:

HE: Hematita especular; HL: Hematita lamelar; HG: Hematita granular. HM: Hematita martítica; MA: Magnetita; GO: Goethita; GT: Goethita terrosa. QL: Quartzo livre; GB: Gibbsita; $H C^{\prime} s=H E+H L+H G$.

Conforme apresentado na Tabela 2 e ilustrado na Figura 3, a quantificação resultante da análise mineralógica global mostra \% significativa de goethita e goethita terrosa, que são fontes de geração de "lamas". A quantidade de material passante nas diversas aberturas de peneira é uma indicação do grau de dispersão. Os resultados apresentados

\begin{tabular}{c|c|c|c|c|c|c|c|c}
\hline \multicolumn{1}{c}{ Análise Química Global (\%) } \\
\hline $\mathrm{Fe}$ & $\mathrm{SiO}_{2}$ & $\mathrm{P}$ & $\mathrm{Al}_{2} \mathrm{O}_{3}$ & $\mathrm{Mn}$ & $\mathrm{TiO}_{2}$ & $\mathrm{CaO}$ & $\mathrm{MgO}$ & $\mathrm{PPC}$ \\
\hline 58,69 & 11,53 & 0,073 & 1,63 & 0,081 & 0,139 & 0,009 & 0,062 & 2,00 \\
\hline
\end{tabular}

Distribuição Granulométrica

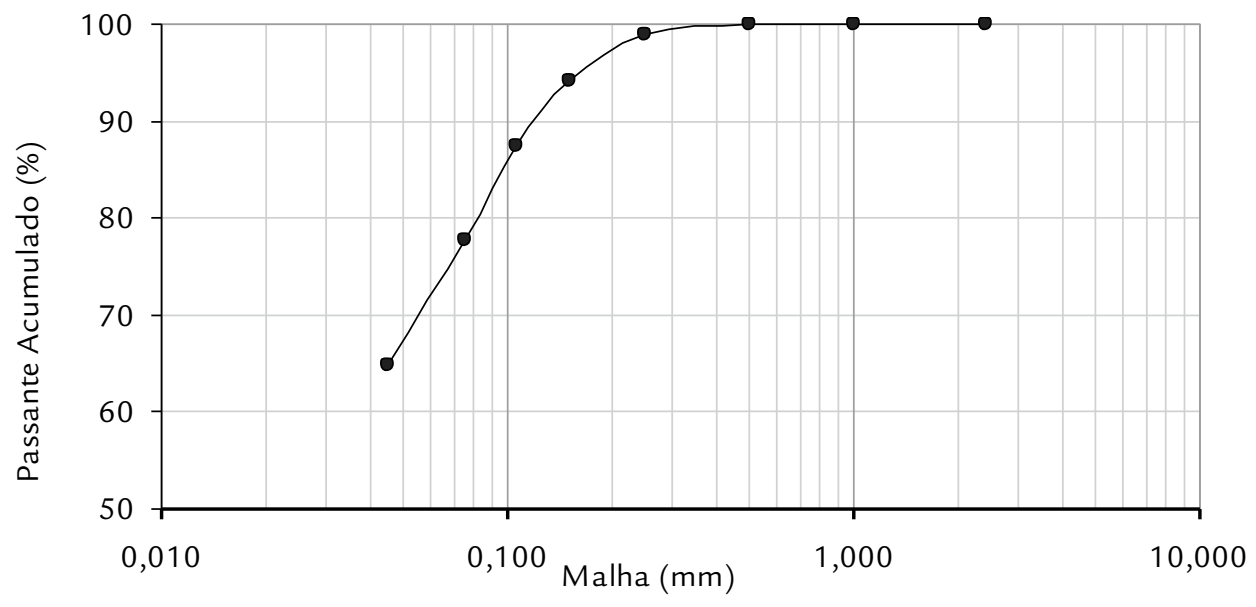

\begin{tabular}{c|c|c|c|c|c|c|c|c|c}
\hline Mineral & HE & HL & HG & HM & MA & GO & GT & QL & GB \\
\hline$\%$ & 2,71 & 19,65 & 25,68 & 28,47 & 1,25 & 7,21 & 1,62 & 13,17 & 0,23 \\
\hline
\end{tabular}

na Figura 4 mostram que a melhor dispersão foi conseguida com o controle de $\mathrm{pH}$ através da adição de hidróxido de sódio. A adição de um polímero (poliacrilato) também proporcionou uma boa dispersão.

Por sua vez, o hexametafosfato não apresentou ação dispersante significativa nas condições testadas. Os resul- tados obtidos para o nível de dispersão nos testes realizados com os reagentes hidróxido de sódio, hexametafosfato de sódio, silicato de sódio, metassilicato de sódio e poliacrilato de sódio estão ilustrados na Figura 5. Houve um aumento no nível de estabilidade da suspensão, principalmente quando se utilizou uma dosagem de $900 \mathrm{~g} / \mathrm{t}$ na polpa, 

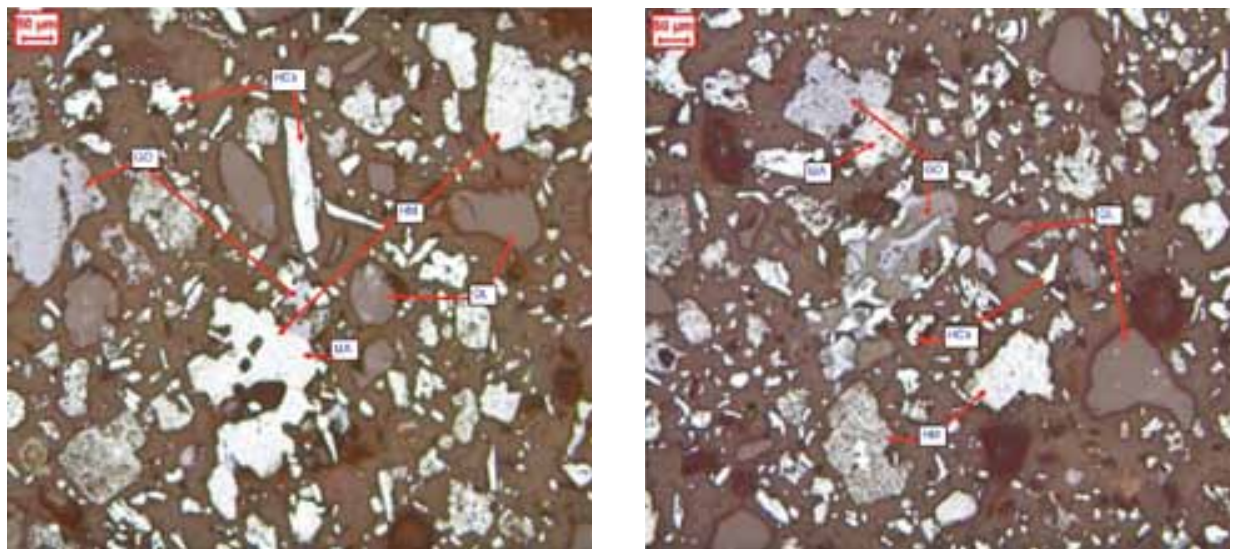

Figura 3

Fotomicrografias da amostra na fração $-0,15 \mathrm{~mm}$.

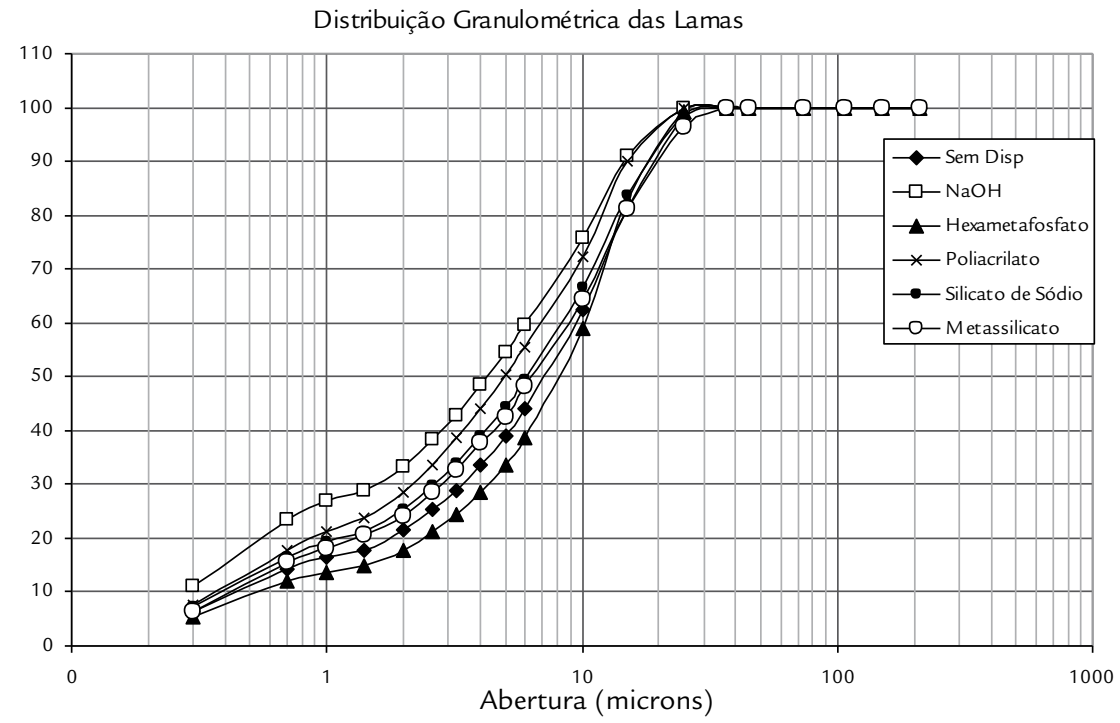

Figura 4

Distribuição granulométrica das lamas geradas nos testes de deslamagem.

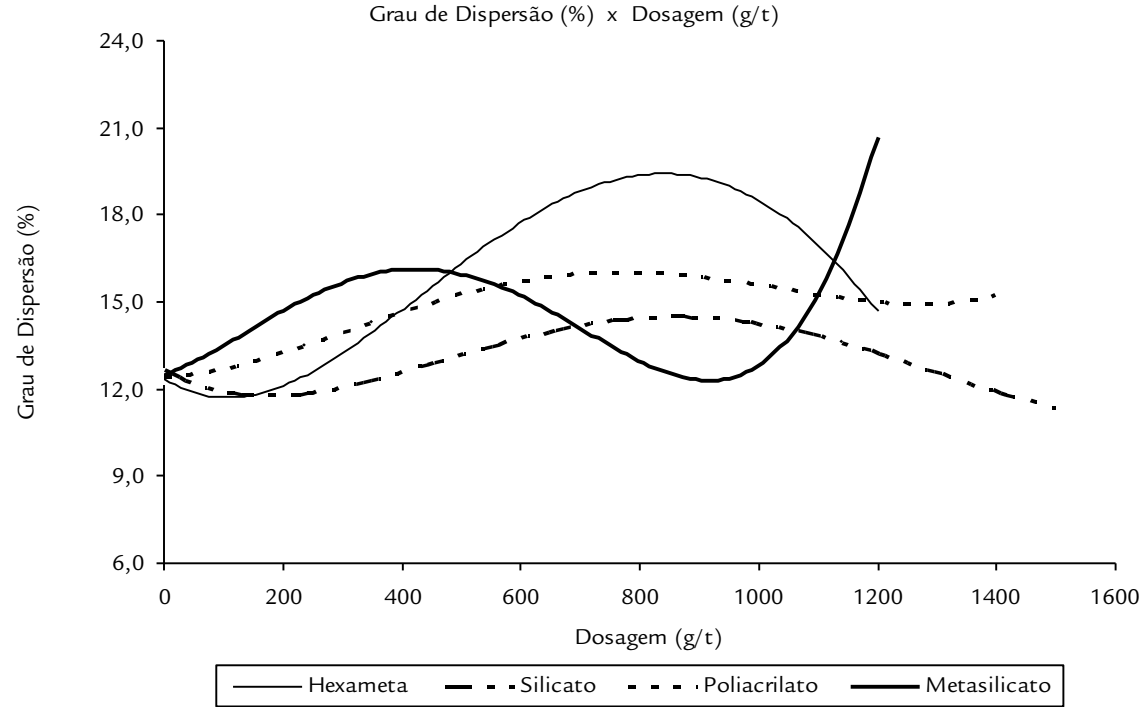

ressaltando-se o efeito do hexametafosfato de sódio. Silva (1994) mostrou a eficiência do hexametafosfato de sódio na estabilidade temodinâmica da polpa para concentração acima de $300 \mathrm{~g} / \mathrm{t}$ e pH acima de 7,0. O hidróxido de sódio atingiu o maior grau de dispersão em $\mathrm{pH}$ na faixa de 9,6 a 9,8. Esse fato confirma o mecanismo de atuação desses reagentes no sentido de promover um aumento e manutenção da carga elétrica na dupla camada elétrica que envolve as partículas em uma suspensão. Os menores níveis de dispersão da polpa ocorrem em $\mathrm{pH}$ natural $(5,4$ a 5,8), resultados similares aos obtidos por Lima (2001) para minérios itabiríticos.

Os resultados da Figura 5 mostram a importância da concentração para a eficiência dos dispersantes metassilicato de sódio e hexametafosfato. A eficiência do metassilicato de sódio
Figura 5

Grau de dispersão em função do $\mathrm{pH}$.

aumenta bastante a partir de uma concentração em torno de $900 \mathrm{~g} / \mathrm{t}$, chegando a um grau de dispersão em torno de $21 \%$. Enquanto isso, o hexametafosfato atinge a eficiência máxima com cerca de $800 \mathrm{~g} / \mathrm{t}$, quando o grau de dispersão é de cerca de $20 \%$. A eficiência do poliacrilato é menos dependente da variação da concentração, com o grau de dispersão estabilizando-se em torno dos $15 \%$ para concentração maiores do que 500 
$\mathrm{g} / \mathrm{t}$. Com o controle do $\mathrm{pH}$, conseguiuse um grau de dispersão máximo em torno dos $19 \%$ em pH 9,5.Como nessa faixa de $\mathrm{pH}$ o quartzo está com carga negativa e $\mathrm{OH}$ - é um de seus íons determinantes de potencial, o aumento do $\mathrm{pH}$ acarreta um aumento dessa carga negativa e, conseqüentemente, uma melhor dispersão (o que está de acordo com os resultados obtidos até $\mathrm{pH}$ em torno de 9,5).

No caso da hematita, ao contrário, a carga elétrica diminuiria até chegar ao seu ponto isoelétrico, prejudicando a dispersão. Após esse $\mathrm{pH}$, a dispersão aumentaria com o aumento da alca- linidade. Portanto o aumento do $\mathrm{pH}$, na faixa muito alcalina, aumentaria a carga elétrica negativa de ambos os minerais, conforme apresentado na Figura 6.

Os testes de deslamagem em bancada foram realizados em dois estágios utilizando-se os reagentes dispersantes propostos no estudo. Através dos resultados do grau de dispersão, obtiveramse as dosagens ótimas dos reagentes que geraram os melhores índices de dispersão (maior estabilidade termodinâmica) da polpa.

De acordo com os resultados da análise química da lama mostrados na
Tabela 3, pode-se observar que os teores de fósforo, alumina e perda por calcinação são mais elevados para os testes com os reagentes dispersantes soda caústica e hexametafosfato de sódio.

$\mathrm{O}$ teor de $\mathrm{Al}_{2} \mathrm{O}_{3}$ varia de $5,37 \%$ até $6,50 \%$. Os testes com adição de hidróxido de sódio (soda caústica) e hexametafosfato de sódio apresentaram os maiores teores de $\mathrm{Al}_{2} \mathrm{O}_{3}$, ou seja, a maior remoção desse contaminante.

Já os reagentes à base de silicato (silicato de sódio, poliacrilato de sódio e metassilicato de sódio) apresentam os maiores percentuais de remoção de lamas para o overflow (sobrenadante).

Grau de Dispersão (\%) $\times$ pH

Figura 6

Grau de dispersão em função do $\mathrm{pH}$.

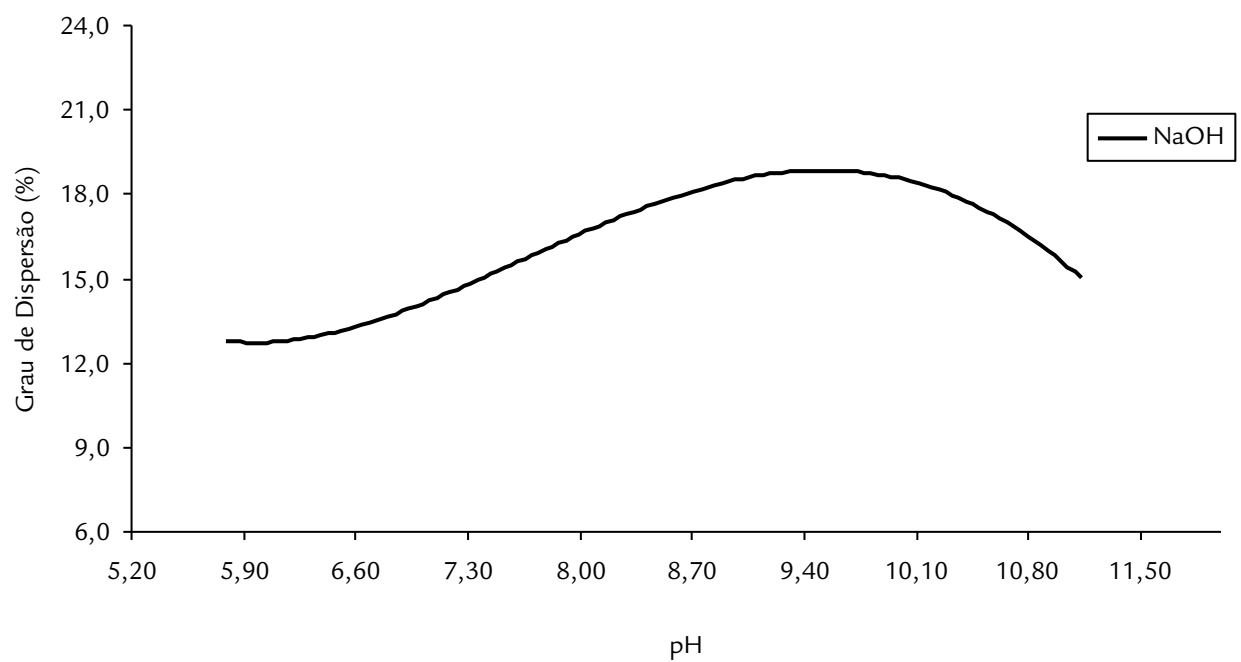

\begin{tabular}{|c|c|c|c|c|c|c|c|c|c|}
\hline \multirow{2}{*}{\multicolumn{2}{|c|}{ Reagente }} & \multirow{2}{*}{ \% Lama } & \multicolumn{7}{|c|}{ Análise Química (\%) } \\
\hline & & & $\mathrm{Fe}$ & $\mathrm{SiO}_{2}$ & $\mathbf{F}$ & & $\mathrm{Al}_{2} \mathrm{O}_{3}$ & Mn & PPC \\
\hline \multicolumn{2}{|c|}{ Sem Dispersante } & 5,29 & 56,22 & 6,37 & \multicolumn{2}{|c|}{0,182} & 5,37 & 0,210 & 6,67 \\
\hline \multicolumn{2}{|c|}{ Soda Cáustica } & 7,94 & 54,08 & 6,61 & \multicolumn{2}{|c|}{0,235} & 6,50 & 0,266 & 7,96 \\
\hline \multicolumn{2}{|c|}{ Hexametafosfato } & 9,03 & 55,18 & 6,42 & \multicolumn{2}{|c|}{0,217} & 6,41 & 0,233 & 6,78 \\
\hline \multicolumn{2}{|c|}{ Silicato de Sódio } & 14,77 & 53,62 & 6,35 & \multicolumn{2}{|c|}{0,204} & 5,59 & 0,233 & 9,95 \\
\hline \multicolumn{2}{|c|}{ Poliacrilato de Sódio } & 15,15 & 55,92 & 6,47 & \multicolumn{2}{|c|}{0,195} & 5,44 & 0,233 & 7,00 \\
\hline \multicolumn{2}{|c|}{ Metassilicato de Sódio } & 14,60 & 55,81 & 6,32 & \multicolumn{2}{|c|}{0,201} & 5,35 & 0,232 & 7,36 \\
\hline \multirow{2}{*}{$\begin{array}{l}\text { Reagente } \\
\text { Dispersante }\end{array}$} & \multicolumn{2}{|c|}{$\begin{array}{l}\text { Recuperação } \\
\text { Flotação (\%) }\end{array}$} & \multicolumn{2}{|c|}{$\begin{array}{c}\text { Recuperação } \\
\text { Global (\%) }\end{array}$} & \multicolumn{4}{|c|}{ Teor do Concentrado } & \multirow{2}{*}{$\begin{array}{c}\text { IS } \\
\text { Gaudir }\end{array}$} \\
\hline & Massa & Met. & Massa & Met. & $\mathrm{Fe}$ & $\mathrm{SiO}_{2}$ & $\mathbf{P}$ & $\mathrm{Al}_{2} \mathrm{O}_{3}$ & \\
\hline Sem Disp. & 54,9 & 67,9 & 52,2 & 64,8 & 67,21 & 0,88 & 0,062 & 0,686 & 7 \\
\hline $\mathrm{NaOh}$ & 63,2 & 62,0 & 57,6 & 61,6 & 67,55 & 0,48 & 0,057 & 0,630 & 9 \\
\hline Hexametafosfato & 58,0 & 69,9 & 54,7 & 59,3 & 67,43 & 0,51 & 0,061 & 0,600 & 10 \\
\hline Poliacrilato & 57,5 & 59,3 & 44,5 & 62,1 & 66,68 & 1,72 & 0,057 & 0,685 & 5 \\
\hline Silicato & 70,2 & 78,5 & 56,6 & 76,7 & 66,91 & 1,16 & 0,055 & 0,680 & 8 \\
\hline Metassilicato & 67,8 & 77,3 & 62,8 & 75,8 & 67,09 & 1,13 & 0,059 & 0,656 & 7 \\
\hline
\end{tabular}


As Figuras $7 \mathrm{a}$ e $7 \mathrm{~b}$ mostram a eficiência da dispersão da polpa com o auxílio de reagente dispersante. A coloração das partículas de quartzo é nítida na Figura 7 b, sem a presença de partículas ultrafinas recobrindo a superfície mineral.

Os maiores teores de sílica presente na lama são aqueles dos ensaios envolvendo os reagentes soda caústica, poliacrilato de sódio e hexametafosfato de sódio. A perda por calcinação teve o

Figura 7

(a) Amostra deslamada sem adição de reagente dispersante. (b) Amostra deslamada com adição de reagente dispersante.

\section{Conclusão}

O uso de um reagente dispersante possibilita a desagregação das partículas, permitindo uma deslamagem mais eficiente de forma a favorecer a seletividade do processo de flotação.

Reagentes como metassilicato de sódio e poliacrilato são eficientes na função de dispersante, mas provocam maior teor nas lamas para os reagentes silicato de sódio, hidróxido de sódio e metassilicato de sódio.

Para o teor de ferro, nas lamas, não houve diferença significativa. A concentração da solução dos reagentes foi de $1,0 \%$ em peso. A dispersão foi feita nas seguintes faixas de $\mathrm{pH}$ : para os silicatos, foi 6,2 a 9,8 e, para o hexametafosfato e poliacrilato de sódio, não houve alteração no $\mathrm{pH}$ e, finalmente, para o hidróxido de sódio, a faixa de trabalho

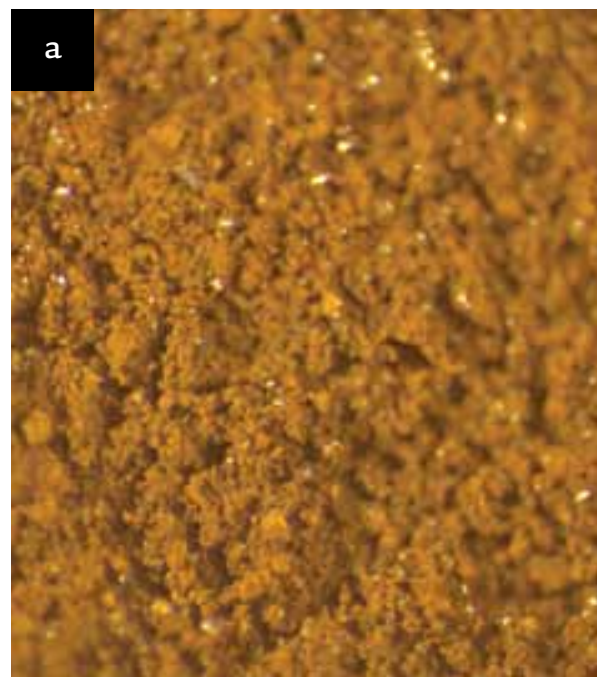

foi de 6,2 a 11,0 conforme apresentado na Figura 6.

Os melhores teores na flotação (refletidos no "Índice de Seletividade de Gaudin") foram observados nos testes com o hidróxido de sódio e com o hexametafosfato, reagentes que não apresentam efeito depressor sobre o quartzo. Os resultados sugerem que o teor do concentrado depende mais do efeito depressor do reagente do que da sua eficiência como dispersante (Tabela 4).

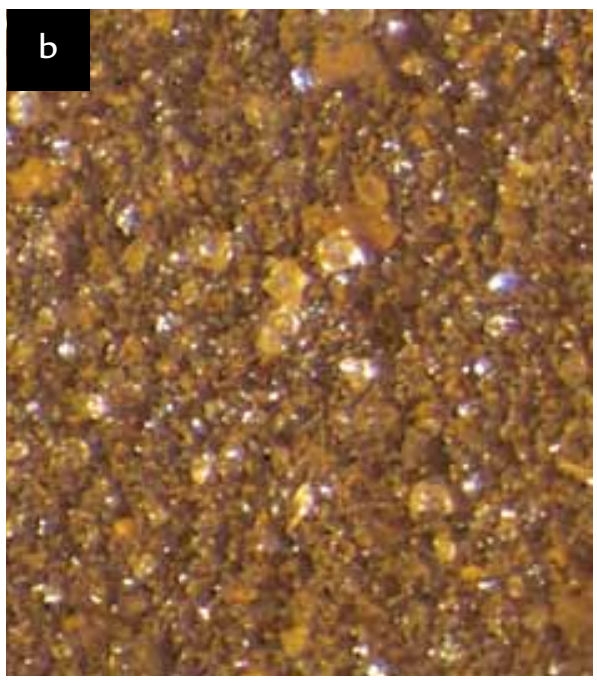

\section{Referências bibliográficas}

BALTAR, C.A.M. Flotação no Tratamento de Minérios. 2008. p.32-43.

CLEMMER, J.B. Flotation of iron ore. In: 8th Ann. Min. Symposium. 1947 January. Proceeding... p. 23-32.

LUZ, J. A. M., ARAUJO, A. C. Fenômenos de agregação: sua influência sobre operações de processamento de minerais. In: ENCONTRO NACIONAL DE TRATAMENTO DE MINÉRIOS E HIDROMETALURGIA, 13. Anais... São Paulo, 1988. p.37-49.

LIMA, N. P. Comportamento de minérios itabiriticos dos complexos Alegria e Fábrica Nova frente aos processos de deslamagem e flotação. Belo Horizonte: Escola de Engenharia da UFMG, 2001. 126p. (Dissertação de Mestrado em Engenharia Metalúrgica e de Minas).

RABELO, P. J. B. Estudos de caracterização e redução do teor de fósforo do minério de ferro da Mina de Alegria, Mariana, MG. Belo Horizonte: Escola de Engenharia, Universidade Federal de Minas Gerais, 1994. 305p. (Dissertação de Mestrado em Engenharia Metalúrgica e de Minas).

SILVA, G. M. A. Estudo sobre o estado de agregação de suspensões de um minério de ferro. Belo Horizonte: Escola de Engenharia da UFMG, 1994. 145p. (Dissertação de Mestrado em Engenharia Metalúrgica e de Minas). 